\title{
RECENT ADVANCES AND FUTURE PROSPECTS IN THE MEDICAL TREATMENT OF OCULAR HYPERTENSION*
}

\author{
BY
}

\author{
R. WEEKERS, E. PRIJOT, AND J. GUSTIN
}

From the Ophthalmological Clinic of the University of Liége, Belgium

THE question whether chronic simple glaucoma should be treated medically or by operation is still a subject of controversy.

Iridencleisis ab externo is one of the best antiglaucomatous operations. It normalizes the resistance to the aqueous flow (Weekers and Prijot, 1952b) and the ocular tension (Weekers and Heintz, 1948) in more than 90 per cent. of cases. Correctly performed, it does not involve any immediate risk; it is very rarely followed by any further complication, and stops or slows down the progress of the visual defects in almost all cases. The modifications in the metabolism of the aqueous humour resulting from the operation can sometimes hasten the evolution of a pre-existent cataract, but this complication is even more frequent after Elliott's trephine or Lagrange's sclerecto-iridectomy.

Medical treatment by parasympathicomimetic miotics does not entail a risk of cataract, though it has other serious disadvantages.

Pilocarpine does not completely normalize the resistance to the aqueous flow (Prijot and Weekers, 1952b) and leaves in the majority of cases a moderate hypertension. Its action is transient, and the study of the curves of tension shows that the instillations, even if repeated four or five times a day, do not ensure a continuous effect.

The inhibitors of the cholinesterases, such as eserine and di-isopropylfluorophosphate (DFP), have a more marked and more prolonged action, but they provoke a painful contraction of the ciliary muscle, and are well tolerated only by the aphakic eye.

From these considerations, it appears that surgical treatment is indicated in the majority of cases of chronic simple glaucoma, but the recent observations summarized below have encouraged us to review this important therapeutic problem.

The work of Goldmann (1949), Grant (1950, 1951), Prijot and Weekers $(1952 a, b)$ and Weekers and Prijot (1952a, b) emphasizes the importance of the hydrodynamic factors in the regulation of the ophthalmotonus $\left(P_{o c}\right)$. This depends on the aqueous flow $(F l)$, the resistance to the flow in the exit channels $(R)$, and the blood pressure in the laminar veins $(P v)$ :

$$
P_{o c}=(F l \times R)+P v
$$

Most forms of treatment, medical or surgical, reduce the resistance to the aqueous flow, e.g., pilocarpine, eserine, DFP, and iridencleisis. But it is also

* Received for publication June 10, 1954. 
possible to reduce the aqueous flow itself, either surgically by retrociliary diathermy (Weekers and Prijot, 1952a) and cyclodialysis (Goldmann, 1951a, b), or medically by Diamox (Becker, 1952), Dibenamine (De Long and Scheie, 1953), and adrenaline (Goldmann, 1951b).

We have studied the mechanism of hypotension during treatment with adrenaline and have found that it reduces the aqueous flow in chronic simple glaucoma (Weekers, Prijot, and Gustin, 1954). The use of adrenaline, either combined with parasympathicomimetic miotics or alone, can produce results upon the tension comparable to those obtained by surgical treatment. It is possible that in the future a combination of therapeutic methods, reducing the flow on the one hand and the resistance on the other, may lessen the need for antiglaucomatous operations.

\section{Material, Methods, and Clinical Features}

The observations recorded below have been made in cases of simple (wideangle) untreated glaucoma. Congestive (narrow-angle) glaucoma was carefully excluded by gonioscopic examination.

The 2 per cent. adrenaline solution was made according to the following formula: $\dagger$

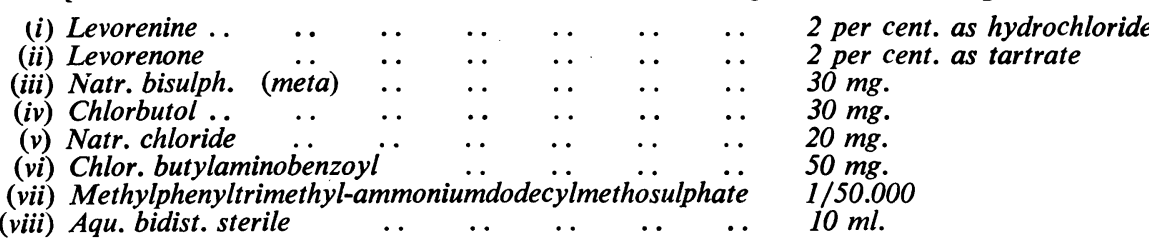

Components (iii) and (iv) stabilize the adrenaline solution; components (vi) and (vii) are wetting agents.

The compression test with the electronic tonometer, which has been previously described (Weekers and Prijot, 1952a), is similar to the tonographic method of Grant (1950). The normal resistance varies from $2 \cdot 7$ to $7 \cdot 3 \mathrm{~mm}$. $\mathrm{Hg}$ (average $4 \cdot 5$ ).

The compression test performed on fourteen cases of simple glaucoma with moderate hypertension (less than $35 \mathrm{~mm}$. $\mathrm{Hg}$ ) shows that the hypotensive action of adrenaline is caused by a reduction of the aqueous flow. This substance normalizes the ophthalmotonus without reducing the resistance to the aqueous flow in the exit channels (Table).

TABLE

EFFECT OF ADRENALINE ON OCULAR TENSION AND RESISTANCE TO AQUEOUS FLOW

\begin{tabular}{c|c|c|c|c}
\hline \multirow{2}{*}{$\begin{array}{c}\text { Number } \\
\text { of } \\
\text { Cases }\end{array}$} & \multicolumn{2}{|c|}{$\begin{array}{c}\text { Mean Ocular Tension } \\
\text { (mm. Hg) }\end{array}$} & \multicolumn{2}{|c}{$\begin{array}{c}\text { Mean } \\
\text { Resistance }\end{array}$} \\
\cline { 2 - 5 } & $\begin{array}{c}\text { Before } \\
\text { Adrenaline }\end{array}$ & $\begin{array}{c}\text { After } \\
\text { Adrenaline* }\end{array}$ & $\begin{array}{c}\text { Before } \\
\text { Adrenaline }\end{array}$ & $\begin{array}{c}\text { After } \\
\text { Adrenaline* }\end{array}$ \\
\hline 14 & 27 & 19 & 10 & 10 \\
\hline
\end{tabular}

* Ocular tension and resistance " afier adrenaline" measured one or two days after instillation. +Made by Henrioul, Namur, Belgium. 
Fig. 1 shows two examples of the effect of a single instillation of adrenaline. This effect lasts one or two days. Fig. 2 shows the persistence of the effect after interruption of the treatment. Fig. 3 shows two series of observations prolonged for several weeks.

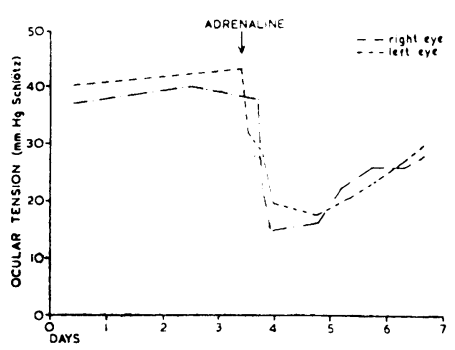

FIG. 1.-Effect of a single instillation of 2 per cent. adrenaline in chronic simple glaucoma.
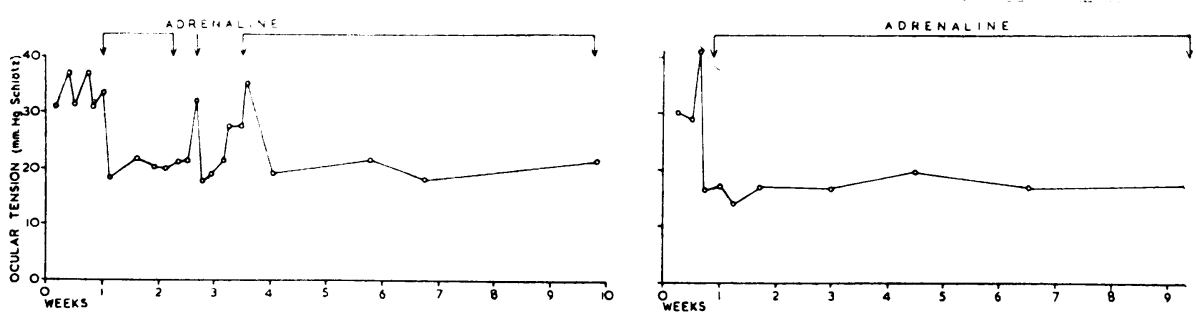

FIG. 3.-Effect of repeated instillations of adrenaline in chronic simple glaucoma for several weeks.

\section{Discussion}

The mechanism of the reduction of the aqueous flow during treatment with adrenaline is not known. Several hypotheses, none of which is satisfactory, have been discussed in a recent publication (Weekers, Prijot, and Gustin, 1954).

At present, however, adrenaline collyrium is very useful in the treatment of chronic simple glaucoma. It normalizes the tension in the majority of cases, and the effect of one instillation frequently lasts as long as 48 hours, so that the instillation of one drop every 2 days is generally sufficient.

Adrenaline provokes only a slight transient sensation of burning, and if the instillation is done in the evening, the mydriasis takes place during the night, and does not bother the patient in the morning.

Local treatment with adrenaline has no effect on the general arterial tension.

By reducing the aqueous flow, adrenaline decreases the ocular tension even when the resistance to the flow is high and irreversible and no longer reacts to the instillation of miotics.

We have now followed some of our cases for 5 months; no patient is presenting any local or general intolerance, but we do not yet know if a longer treatment will provoke reaction.

Another question is whether the reduction of the flow may not threaten the transparency of the lens. It seems that this is not so; the adrenaline reduces the flow but does not stop it entirely. It is not uncommon to observe one or more 
aqueous veins, when the effect on the ocular tension is pronounced. Delmarcelle (1954) has reached the same conclusion by direct measurement of the aqueous flow. The experience of retrociliary non-perforating diathermy also shows that a reduction of the flow does not alter the crystalline lens, even after many months or years.

Sometimes adrenaline may be used with parasympathicomimetic miotics. DukeElder (1940) advised the use of adrenaline and eserine simultaneously. His aim was to avoid mydriasis, but this association is also justified by its double action: reducing the aqueous flow on the one hand and the resistance to the flow on the other. Our present investigations were performed with DFP which has a longer effect than eserine. In a concentration of 0.05 per cent. this substance is not easily tolerated, but it seems that very weak solutions $(0.01$ per cent.) are easily borne by the patient and are still efficient (Leopold, 1949; Leopold and Cleveland, 1953; Raiford, 1949). The combination of adrenaline and DFP can normalize the tension even in difficult cases of luxation of the lens, thrombosis of the central vein, exfoliative glaucoma, etc.

Treatment with adrenaline alone or in association with a miotic is contraindicated in narrow-angle glaucoma. In those cases, the closure of the iridocorneal angle during mydriasis provokes a considerable increase of resistance to the flow, and promotes immediate hypertension. A previous instillation of DFP does not prevent the mydriasis due to adrenaline. Duke-Elder (1940) stated that:

The action of the adrenaline group of drugs should be confined to simple primary glaucoma, their use in chronic congestive glaucoma is questionable and in acute glaucoma dangerous.

Unforeseen attacks of hypertension may be the reason why antiglaucomatous treatment with adrenaline has been given up, in spite of the good results claimed by Hamburger (1923). To-day, this complication can be avoided by gonioscopy.

We have treated forty cases of simple glaucoma without complications. A single instillation made deliberately in a case of narrow-angle glaucoma provoked an immediate and considerable attack of hypertension; it was easily neutralized by the ingestion of Diamox and the instillation of pilocarpine.

\section{Summary}

Adrenaline provides an excellent local treatment for chronic simple glaucoma and for some cases of secondary glaucoma. It is strictly contraindicated in congestive (narrow-angle) glaucoma.

Its action results from a reduction of the aqueous flow, but the mechanism of this reduction is unknown.

The association of a medication reducing the aqueous flow with a medication reducing the resistance to the flow (e.g. adrenaline, DFP) is followed by very pronounced effects on the tension. It is possible that in the future this combined medical treatment will reduce the necessity for surgery.

\section{REFERENCES}

BeCKer, B. (1954). Amer. J. Ophthal., 37, 13.

DeLMARCELle, . (1954). Unpublished observations.

DE LONG, S. L., and ScHeIE, H. G. (1953). Arch. Ophthal. (Chicago), 50, 289.
Duke-Elder, S. (1940). "Text-book of Ophthalmology", vol. 3, p. 3396. Kimpton, London. 
Hamburger, C. (1923). Med. Klin., 19, 1224. Abs. in Klin. Mbl. Augenheilk., 71, 810.

GoldmanN, H. (1949). Ophthalmologica (Basel), 118, 496. (1951a). Ibid., 121, 94.

(1951b). Ann. Oculist. (Paris), 184, 1086.

Grant, W. M. (1950). Arch. Ophthal. (Chicago), 44, 204. (1951). Ibid., 46, 113.

LEOPOLD I. H. (1949). Amer. J. Ophthal., 32, 579.

- and Cleveland, A. F. (1953). Ibid., 36, 226.

Prijot, E., and Weekers, R. (1952a). Ophthalmologica (Basel), 123, 1.

- (1952b). Ibid., 124, 12.

RAIFORD, M. B. (1949). Amer. J. Ophthal., 32, 1399.

WeEkers, R., and Heintz, A. (1948). Bull. Soc. belge Ophtal., No. 90, 494. and Prijot, E. (1952a). Ophthalmologica (Basel), 123, 365. (1952b). Ibid., 124, 166.

- - , and Gustin, J. (1954). Ibid. (in the press). 